\title{
Correlation of heart rate/ST slope and coronary angiographic findings
}

\author{
RAPHAEL BALCON, NICHOLAS BROOKS, CLIVE LAYTON \\ From the London Chest Hospital and Cardiothoracic Institute, London
}

SUMMARY The heart rate/ST slope was evaluated in 49 patients undergoing routine investigation for possible coronary artery disease. The slope correctly predicted the absence of any $75 \%$ stenoses in the seven patients to whom this applied; it was, however, correct for only four of 30 with one stenosis, one of 10 with two, and neither of the patients with three. Distinct slope ranges were not found, and the previously published ranges said to be specific for no significant stenosis and one, two, and three vessel disease were not.

The prognosis in patients with coronary heart disease is closely related to the severity and extent of their arterial lesions. Accurate knowledge of this pathological anatomy is highly desirable for clinical management, but it is neither feasible nor in fact desirable to perform angiography on all patients. If, however, selection for angiography is based on the severity of angina patients with mild symptoms but with extensive disease will miss the opportunity for prophylactic surgery, and some with chest pain but normal coronary arteries will be wrongly diagnosed. Thus noninvasive methods to assess severity are needed.

Exercise testing has been used predominantly as a screening test to detect the presence of coronary disease, and its value in these circumstances is highly dependent on the prevalence of the disease in the population under study. In patients with angina, however, its main value should be in assessing the severity of the disease. Changes in both heart rate and ST segment displacement during exercise are related to the occurrence of myocardial ischaemia, and a variable that takes account of both may be more reliable than either alone. The use of a heart rate/ST segment slope was first described in 1979. ${ }^{1}$ The authors used an ergometer exercise test and monitored three bipolar chest leads. They showed a good correlation between the slope and the number of diseased vessels. In 1980 a similar test was described by Elamin et al, ${ }^{2}$ but 13 leads were monitored. In a later report of the results in 120 patients they found absolute agreement

Requests for reprints to Dr Raphael Balcon, London Chest Hospital, Bonner Road, London E2 9JX.

Accepted for publication 15 May 1984 between the maximum heart rate/ST slope and a coronary arteriographic assessment of disease severity. ${ }^{3}$ Slope ranges were defined that divided patients into those with no major (75\%) stenosis, and those with one, two, or three vessel disease. There was no overlap of data. Because of the great potential of this new method we carried out a study in an attempt to confirm these findings.

\section{Patients and methods}

Patients complaining of recurrent chest pain with suspected coronary disease who were admitted for coronary arteriography were included in the study. Availability of exercise laboratory time was the only factor that determined which patients were tested since all such patients being investigated could not be included. Patients with cardiac pain at rest, coincidental valvar disease, systemic hypertension (blood pressure $>160 / 90 \mathrm{~mm} \mathrm{Hg}$ ), heart failure, conduction disturbances, or with extrasystoles with a frequency of more than one in 10 sinus complexes were excluded. Treatment with beta adrenergic blocking agents was continued, but calcium antagonists were withdrawn and cardiac glycosides were not used.

\section{EXERCISE TEST}

The published protocol was followed strictly. The 12 conventional electrocardiographic leads and CM5 were recorded on a Mingograph ink jet recorder before and during the ergometer test. The steady heart rate at the end of each exercise stage was calculated from the RR interval on the electrocardiogram, and the level of the ST segment $0.08 \mathrm{~s}$ after the end of 
the QRS complex and in relation to the level of two consecutive PR segments was measured using a magnifying glass fitted with a graticule calibrated in $0.1 \mathrm{~mm}$ divisions. Great efforts were made to ensure a stable baseline, and records were rejected if this was not achieved. Measurements were not made in leads which showed more than $0.5 \mathrm{~mm}$ ST segment displacement in the resting record. The data were analysed using a North Star computer. It was programmed to derive the maximum heart rate/ST slope which had a linear regression with a correlation coefficient significant at the $5 \%$ level.
ANGIOCARDIOGRAPHY

Selective coronary arteriography in multiple projections and left ventriculography in the $30^{\circ}$ right anterior oblique projection were carried out using standard techniques. The percentage narrowing of the coronary artery was measured in the projection which showed maximum encroachment on the lumen. Significant coronary disease was defined as described ${ }^{2}$ as luminal narrowing of the diameter by $>75 \%$ (grades 3 and 4 (Table)) in any of the three major coronary arteries. These were the right coronary artery, or its posterior descending branch when this

Table Clinical and angiographic data on 49 patients with suspected coronary artery disease

\begin{tabular}{|c|c|c|c|c|c|c|c|c|c|c|c|c|c|c|c|}
\hline \multirow{2}{*}{$\begin{array}{l}\text { Jase } \\
\text { Vo }\end{array}$} & \multirow{2}{*}{$\begin{array}{l}\text { Age (yr) } \\
\text { and } \\
\text { sex }\end{array}$} & \multicolumn{3}{|l|}{ Angina } & \multicolumn{5}{|c|}{ Coronary angiographyt } & \multicolumn{3}{|c|}{ Left ventricular angiogram } & \multirow{2}{*}{$\begin{array}{l}\text { Lead } \\
\text { with } \\
\text { max slope }\end{array}$} & \multirow{2}{*}{$\begin{array}{l}\text { Heart } \\
\text { ratel } \\
S T \text { slope }\end{array}$} & \\
\hline & & Grade & $\begin{array}{l}\text { Duration } \\
\text { (mth) }\end{array}$ & $\begin{array}{l}\text { Previous } \\
\text { infarct }\end{array}$ & $\begin{array}{l}\text { Left } \\
\text { main }\end{array}$ & $L A D$ & $L C X$ & $R C A$ & $\begin{array}{l}75 \% \\
\text { stenosis }\end{array}$ & Anterior & Apical & Inferior & & & \\
\hline 1 & $52 \mathrm{M}$ & 1 & 14 & & & 4 & 2 & & 1 & $\mathbf{N}$ & $\mathrm{N}$ & $\mathbf{N}$ & & 0 & \\
\hline 2 & $42 \mathrm{M}$ & 1 & $<1$ & + & & 1 & 1 & 3 & 1 & $\mathrm{~N}$ & $\mathrm{~N}$ & $\mathrm{~N}$ & & 0 & \\
\hline 3 & $54 M$ & 2 & 3 & & & 1 & 3 & 1 & 1 & $\mathbf{N}$ & $\mathbf{N}$ & $N$ & & 0 & \\
\hline 4 & $53 M$ & 2 & 11 & & & & & 1 & 0 & $\mathbf{N}$ & $\mathrm{N}$ & $\mathrm{N}$ & & 0 & \\
\hline 5 & $39 M$ & 3 & 12 & + & & & & 3 & 1 & $\mathbf{N}$ & $\mathrm{N}$ & $\mathrm{H}$ & aVL & 20 & \\
\hline 6 & $36 M$ & 2 & 18 & & & & & 2 & 0 & $\mathrm{~N}$ & $\mathrm{~N}$ & $\mathbf{N}$ & & 0 & \\
\hline 7 & $49 M$ & 4 & 18 & + & & 2 & 1 & 3 & 1 & $\mathrm{~N}$ & $\mathbf{N}$ & $\mathrm{H}$ & V6 & 8 & \\
\hline 8 & $51 \mathrm{M}$ & 3 & 9 & & & 4 & 3 & & 2 & $N$ & $\mathrm{~N}$ & $N$ & V1 & 10 & \\
\hline 9 & $49 M$ & 1 & 4 & & & 1 & 3 & & 1 & $\mathbf{N}$ & $N$ & $N$ & & 0 & \\
\hline 0 & $38 \mathrm{~F}$ & 4 & 6 & & & $N$ & $\mathrm{~N}$ & & 0 & $\mathrm{~N}$ & $\mathrm{~N}$ & $\mathrm{~N}$ & V4 & 6 & \\
\hline 11 & $49 M$ & 4 & 3 & + & & 3 & 4 & & 2 & $\mathrm{~N}$ & $\mathrm{~N}$ & $\mathbf{N}$ & & 0 & \\
\hline 2 & $44 M$ & 0 & 2 & & & 1 & & & 0 & $\mathbf{N}$ & $\mathbf{N}$ & $\mathbf{N}$ & II & 7 & \\
\hline 13 & $66 M$ & 2 & 6 & & 1 & 1 & & 4 & 1 & $\mathrm{~N}$ & $\mathbf{N}$ & $\mathrm{N}$ & II & 101 & \\
\hline 4 & $58 \mathrm{M}$ & 3 & 12 & & & 4 & 1 & & 1 & $\mathrm{~N}$ & $\mathrm{~N}$ & $\mathrm{~N}$ & $\mathrm{aVF}$ & 20 & \\
\hline 15 & $39 M$ & 2 & 8 & & & 3 & & & $i$ & $\mathrm{~N}$ & $\mathrm{H}$ & $\mathrm{N}$ & $\mathrm{aVF}$ & 31 & \\
\hline 6 & $61 M$ & 2 & 42 & + & & 3 & 1 & 1 & 3 & $\mathrm{~N}$ & $\mathrm{~N}$ & A & II & 20 & \\
\hline 17 & $41 M$ & 1 & 2 & & & 1 & $i$ & 3 & 1 & $\mathrm{~N}$ & $\mathrm{~N}$ & $\mathrm{H}$ & I & 8 & \\
\hline 18 & $51 \mathrm{M}$ & 2 & 8 & + & & 2 & & 4 & 1 & $\mathrm{~N}$ & $\mathrm{~N}$ & A & & 0 & \\
\hline 19 & $62 M$ & 2 & 8 & + & & 1 & & 4 & 1 & $\mathrm{~N}$ & $\mathrm{~N}$ & $\mathbf{N}$ & I & 6 & \\
\hline$? 0$ & $56 M$ & 1 & 4 & + & & 2 & 1 & 4 & 1 & $\mathbf{N}$ & $\mathrm{N}$ & $\mathrm{H}$ & & 0 & \\
\hline 1 & $52 M$ & 1 & 7 & + & 1 & 3 & 1 & 4 & 2 & $\mathrm{~N}$ & $\mathbf{N}$ & $\mathrm{H}$ & V5 & 18 & \\
\hline$! 2$ & $57 M$ & 2 & 1 & & & 3 & & & 1 & $\mathrm{~N}$ & $\mathbf{N}$ & $\mathbf{N}$ & V5 & 53 & \\
\hline 3 & $64 M$ & 2 & 4 & + & & 2 & & 4 & 1 & $\mathrm{~N}$ & $\mathrm{~N}$ & A & & 0 & \\
\hline$? 4$ & $56 M$ & 3 & 60 & + & 1 & 2 & 3 & 4 & 2 & $\mathrm{~N}$ & $\mathrm{H}$ & A & & 0 & \\
\hline .5 & $58 \mathrm{M}$ & 2 & 72 & & & 3 & & & 1 & $\mathrm{~N}$ & $\mathrm{~N}$ & $\mathbf{N}$ & CM5 & 62 & \\
\hline ?6 & $55 M$ & 1 & 13 & & & 4 & & 1 & 1 & $\mathrm{~N}$ & $\mathrm{H}$ & $\mathrm{N}$ & CM5 & 19 & \\
\hline$? 7$ & $62 M$ & 0 & 2 & + & & 1 & 1 & 4 & 1 & $\mathrm{~N}$ & $\mathrm{~N}$ & $\mathrm{H}$ & V4 & 23 & \\
\hline 8 & $59 M$ & & 5 & & & 3 & & & 1 & $\mathrm{~N}$ & $N$ & $N$ & & 0 & \\
\hline$? 9$ & $47 M$ & 2 & 18 & & & 1 & 1 & 3 & 1 & $\mathrm{~N}$ & $\mathrm{~N}$ & $N$ & & 0 & ... \\
\hline 30 & $62 M$ & 4 & 7 & & & 3 & & 1 & 1 & $\mathrm{~N}$ & $\mathrm{~N}$ & $\mathrm{~N}$ & & 0 & \\
\hline 31 & $55 \mathrm{M}$ & 0 & 15 & + & & 2 & & 4 & 1 & $\mathrm{~N}$ & $\mathrm{~N}$ & A & V6 & 21 & \\
\hline 32 & $57 \mathrm{M}$ & 4 & 2 & & & 1 & & & 0 & $\mathrm{~N}$ & $\mathrm{~N}$ & $\mathbf{N}$ & & 0 & 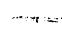 \\
\hline 33 & $57 M$ & 0 & 18 & & 1 & 2 & 4 & 3 & 2 & $\mathrm{~N}$ & $\mathrm{H}$ & A & V4 & 52 & \\
\hline 54 & $52 \mathrm{M}$ & 4 & 72 & & & 1 & 1 & 1 & 0 & $\mathbf{N}$ & $\mathbf{N}$ & $\mathrm{N}$ & & 0 & \\
\hline 35 & $47 \mathrm{M}$ & 2 & 12 & & & 2 & 3 & 3 & 2 & $\mathrm{~N}$ & $\mathrm{~N}$ & $\mathbf{N}$ & III & 2 & \\
\hline 36 & $57 \mathrm{M}$ & 1 & 12 & & & 3 & 1 & 1 & $\overrightarrow{1}$ & $\mathbf{N}$ & $\mathbf{N}$ & $\mathbf{N}$ & III & 3 & \\
\hline 37 & $51 M$ & 3 & 96 & + & & 4 & 3 & $2^{\star}$ & 2 & $\mathrm{~N}$ & $\mathbf{H}$ & $\mathrm{N}$ & & 0 & \\
\hline 38 & $47 \mathrm{M}$ & 2 & 18 & & & 2 & & & 0 & $\mathrm{~N}$ & $\mathrm{~N}$ & $\mathrm{~N}$ & & 0 & \\
\hline 39 & $59 M$ & 2 & 96 & + & 2 & 2 & & 4 & 1 & $\mathrm{~N}$ & $\mathrm{~N}$ & $\mathrm{~N}$ & CM5 & 64 & \\
\hline 10 & $55 \mathrm{M}$ & 4 & 12 & & & 3 & & $\star$ & 1 & $\mathrm{~N}$ & $\mathrm{~N}$ & $\mathrm{~N}$ & III & 29 & \\
\hline 11 & $52 \mathrm{M}$ & 4 & 3 & + & & 3 & & 3 & 2 & $\mathrm{~N}$ & $\mathrm{~N}$ & $\mathrm{D}$ & & 0 & \\
\hline 12 & $58 M$ & 4 & 25 & + & & 3 & 3 & 3 & 3 & $\mathrm{~N}$ & $\mathrm{H}$ & $\mathbf{N}$ & CM5 & 39 & \\
\hline 13 & $55 M$ & 2 & 12 & & & 3 & & 2 & 1 & $\mathrm{~N}$ & $\mathrm{H}$ & $\mathbf{N}$ & V5 & 49 & \\
\hline 14 & $58 \mathrm{M}$ & 4 & 108 & & 1 & 3 & & 4 & 2 & $\mathrm{~N}$ & $\mathbf{N}$ & $\mathbf{N}$ & & 0 & \\
\hline 15 & $45 M$ & 1 & 7 & & & 3 & 2 & 3 & 2 & $\mathrm{~N}$ & $\mathrm{H}$ & $\mathbf{N}$ & I & 13 & \\
\hline 16 & $46 M$ & 2 & 72 & & & & 4 & 1 & 1 & $\mathrm{~N}$ & $\mathbf{H}$ & $\mathbf{N}$ & & 0 & \\
\hline 17 & $51 M$ & 3 & 120 & + & & 1 & 3 & 1 & 1 & $\mathrm{~N}$ & $\mathrm{H}$ & $\mathbf{H}$ & & 0 & \\
\hline 18 & $49 M$ & 3 & 10 & + & & 4 & 1 & 1 & 1 & $\mathrm{~N}$ & $\mathrm{H}$ & $\mathbf{N}$ & II & 55 & \\
\hline 19 & $55 \mathrm{M}$ & 3 & 68 & & & 3 & & & 1 & $\mathbf{N}$ & $\mathbf{N}$ & $\mathbf{N}$ & II & 66 & \\
\hline
\end{tabular}

0 , none; 1 , pain on extra exertion; 2 , pain on normal exertion; 3 , pain on mild exertion; 4 , pain at rest.

No of stenoses.

-, yes; LAD, left anterior descending; LCX, left circumflex; RCA, right coronary. N, normal; H, hypertensive; A, akinetic, D, dyskinetic. 
was the only major branch to the left ventricle, the left main, the left anterior descending proximal to either its major diagonal or first septal branches or to both, and the left circumflex artery proximal to its lateral branches or its major lateral branch when this constituted the principal termination of the main vessel. Coronary obstructions of $<75 \%$ (grades 1 and 2 (Table)) were noted but ignored for the purposes of this comparison. Patients were classified as having no significant disease or one, two, or three vessel disease. The heart rate/ST slopes and angiographic data were assessed independently, the observer having no knowledge of the other findings. The slope ranges were then used to predict the severity of the disease, and these predictions were compared with the actual angiographic findings.

\section{Results}

Seventy six patients met the clinical criteria and were considered for the test, but 24 of these were unsuitable because of abnormalities on the resting electrocardiogram. The record was unsatisfactory in three tests. The heart rate/ST slope could therefore be analysed in 49 patients. A significant slope occurred in 27 patients. The maximum significant slope occurred in 10 of the 13 leads, most commonly in lead II (five cases) and then CM5 (four cases). A wide range of coronary disease was found. Seven patients had no main trunk lesions of $>75 \%, 30$ had one, 10 two, and two three stenoses of at least $75 \%$.

The absence of any $75 \%$ stenoses was correctly predicted in all seven patients (no significant slope or slope range 3-11). It was correct for three of 30 patients with one vessel disease (slope range 13-21), for one of 10 patients with two vessel disease (slope range 32-59), and for neither patient with three vessel disease (slope range 69-137). The slope was therefore correct for only $24 \%$ of patients. Seven patients had slopes between the ranges.

\section{Discussion}

The results of this study are contrary to those previously reported..$^{1-3}$ The published methods 23 were followed meticulously initially under the guidance of two of the authors of one of the earlier reports (MSE and DASGM). Where there was still doubt concerning the angiographic definition of a major vessel this was clarified by further communication. The conflicting results cannot therefore be explained by methodological differences.

Patient selection may have been different in that a higher proportion of those in this study had one vessel disease, although they appear to be similar in terms of age and the clinical variables mentioned. There was also only one female patient. If, however, the test, has different sensitivity in different populations it-like other forms of exercise electrocardiography - would be of very little value as a screening test, although its value in a clearly defined population would not necessarily be limited.

The Leeds group consider that the heart rate/ST slope is an indicator of the severity of myocardial ischaemia and that this is constant with all coronary stenoses $\geqslant 75 \%$. They also imply that the amount of ischaemic muscle is important since only lesions in the proximal main vessels are detected. The further implication of this is that there is a "threshold" amount of ischaemic muscle. The coronary circulation is very variable, and patients who would fall into the same disease category might have considerable differences in the amount of potentially ischaemic myocardium. For instance, the right coronary artery might supply only a small area of the left ventricle through one inferior left ventricular branch, and the threshold for the detection of ischaemia might never be reached, and yet it would be classified in the same way as a much larger right branch supplying perhaps the whole inferior wall and the majority of the interventricular septum through three inferior left ventricular branches. Similarly the left anterior descending artery normally supplies considerably more left ventricular myocardium than the right or circumflex arteries, and yet an appropriate lesion in any of these would be classified as one vessel disease.

The degree of stenosis is difficult to measure accurately, and reproducibility is poor ${ }^{4}$ In addition, variation of vascular tone may alter the apparent degree of stenosis. $^{5}$ The effect of stenoses is dependent on the level of demand so that it requires approximately $85 \%$ obstruction to limit resting coronary flow, whereas maximal flow is limited by $30 \%$ obstruction. ${ }^{6}$ It is very difficult to accept, therefore, that the $75 \%$ stenosis level could be so critical and that, for instance, a $70 \%$ narrowing in a major vessel does not produce a substantial ischaemic zone sufficient to produce a significant heart rate/ST slope great enough to indicate significant disease.

Elamin et al found no stenoses between $50 \%$ and $75 \%$, which is surprising. They suggest that this might have been due to bias on the part of those reporting the angiograms, there being a tendency to call what was thought to be significant stenosis as $\geqslant 75 \%$ and insignificant as $<75 \%$. This is highly likely to be so, but it also casts further doubt on the accuracy of the $75 \%$ measurement.

Because of these difficulties any relation between the heart rate/ST slope and the angiographic assessment would not be expected to be very close, and the results of this study were therefore not unexpected, although better was hoped for. 
Equally, it was not surprising that there was an overlap of data with values found between the published slope ranges. The authors were also surprised by their findings and postulated that it was due to a sudden increase in the degree of obstruction at a level where small changes lead to large reductions in resting coronary flow. They suggest that the time spent at this critical level is so short that, by chance, they have not observed any patient at that stage. It would seem much more likely that because of the variability of the coronary circulation and the possibility of alteration of other physiological variables-such as ventricular volume and contractility - that patients would have a period during which the results of the test would be variable.

The present data show the expected continuum of slopes with no clearly defined ranges, and despite meticulous adherence to the test protocol the previously described relation between heart rate/ST slope and angiographic findings has not been confirmed. This was also the experience of Quyyumi et al who recently reported the results of this test in a similar group of patients. ${ }^{7}$

This work was supported by a British Heart Foundation grant.

\section{References}

1 Berenyi I, Hajduczki I, Boszormenyi E. Terheles alatti ST szakasz depressio quantitativ ertekelese a coronariabetegseg sulyossaganak megitelesere. Cardiologica Hungarica 1979; 8: 295-302.

2 Elamin MS, Mary DASG, Smith DR, Linden RJ. Prediction of severity of coronary artery disease using slope of submaximal ST segment/heart rate relationship. Cardiologica Hungarica 1979; 8: 295-302.

3 Elamin MS, Boyle R, Kardash MM, et al. Accurate detection of coronary heart disease by new exercise test. Br Heart F 1982; 48: 311-20.

4 De Rouen TA, Murray JA, Owen W. Variability in the analysis of coronary arteriograms. Circulation 1977; 55: 324-8.

5 Rafflenbeul W, Urthaler F, Russell RO, Lichtlen P, James TN. Dilatation of coronary artery stenoses after isosorbide dinitrate in man. Br Heart 7 1980; 43: 546-9.

6 Gould KL, Lipscomb K, Hamilton GW. Physiologic basis for assessing critical coronary stenosis: instantaneous flow response and regional distribution during coronary hyperemia as measures of coronary flow reserve. $\mathrm{Am}$ f Cardiol 1974; 33: 87-94.

7 Quyyumi AA, Raphael MJ, Wright C, Bealing L, Fox KM. Inability of the ST segment/heart rate slope to predict accurately the severity of coronary artery disease. $\mathrm{Br}$ Heart f 1984; 51: 395-8. 